\title{
Study on the anatomical spectrum of hypospadias and the age at presentation for surgery
}

\section{*Ravibindu Ranawaka ${ }^{1}$}

Sri Lanka Journal of Child Health, 2019; 48(4): 305-307

\begin{abstract}
Introduction: Textbooks classify $60 \%$ of hypospadias as distal and $40 \%$ as proximal based on the anatomical location of the urinary meatus. Studies on the detailed spectrum of hypospadias however, are rare.
\end{abstract}

Objectives: To describe the anatomical spectrum of hypospadias and the age at presentation for surgery.

Method: This descriptive study analysed data of 100 consecutive hypospadias reconstructions performed by the author at the day surgical unit of The Lady Ridgeway Hospital for Children (LRH) from $1^{\text {st }}$ January 2014 to $28^{\text {th }}$ February 2018. Data were collected retrospectively by the author by going through the surgical clinic records and author's operations log book. Ethical approval was obtained from the LRH ethical review committee.

Results: Of the total 100 hypospadias, 74 had a distally placed urinary meatus and the rest had a proximally placed meatus. Children were divided into four categories according to the age at presentation for surgery. Only $31 \%$ presented for surgery before 2 years of age.

Conclusions: In the study carried out at the LRH day surgical unit $74 \%$ of the hypospadias had a distally placed urinary meatus and $26 \%$ a proximally placed meatus. In this study only $31 \%$ presented for surgery before 2 years of age.

DOI: http://dx.doi.org/10.4038/sljch.v48i4.8822

(Key words: Anatomical spectrum of hypospadias, timely surgery for hypospadias, hypospadias reconstruction in children)

${ }^{1}$ Consultant Paediatric Surgeon, Lady Ridgeway Hospital for Children, Colombo, Sri Lanka

*Correspondence: rravibindu@yahoo.com

orcid.org/ 0000-001-9150-7904

(Received on 27 December 2018; Accepted after revision on 22 February 2019)

The author declares that there are no conflicts of interest

Personal funding was used for the project.

Open Access Article published under the Creative

Commons Attribution CC-BY (c) (P)

\section{Introduction}

Textbooks classify $60 \%$ of hypospadias as distal and $40 \%$ as proximal based on the anatomical location of the urinary meatus ${ }^{1}$. Studies on detailed spectrum of hypospadias however, are rare. Knowledge on the detailed anatomical location of urinary meatus helps to plan reconstruction and to predict post-surgical expectations. Timely surgical reconstruction before the child acquires potty training i.e. 2 years of age as per the Royal Manchester Children's Hospital in UK protocol, facilitates achieving the optimal anatomical and psychological development ${ }^{2,3}$. Although delayed presentation for surgery is common in Sri Lanka, studies on this delay are few. Paediatricians as the primary care lead clinicians can play an important role in facilitating timely surgery by motivating parents.

The anatomical defects in hypospadias include; opened up prepuce and opened up glans penis, glanular and penile shaft chordee, mal-developed and scarred urethral tube, underdeveloped preputial and penile shaft skin, divergent and underdeveloped corpus spongiosum and underdeveloped Dartos muscle. The basic steps in hypospadias reconstruction are; dissection correcting penile chordee, urethral tube reconstruction over a urethral catheter, corpus spongiosum reconstruction, getting Dartos muscle and penile skin cover over repair and, reconstruction of glans penis and prepuce $e^{4,5,6}$.

\section{Objectives}

1. To describe the anatomical spectrum of hypospadias

2. To describe the age at presentation for surgery

\section{Method}

This descriptive study analysed data of 100 consecutive hypospadias reconstructions performed by the author at the day surgical unit of The Lady Ridgeway Hospital for Children (LRH) from $1^{\text {st }}$ January 2014 to $28^{\text {th }}$ February 2018. Data were collected retrospectively by the author by going through the surgical clinic records and author's operations log book. Ethical approval was obtained from the LRH ethical review committee.

The anatomical site of the urinary meatus was classified during surgical dissection by the author 
(e.g. after dissection of penile chordee according to the accepted protocol for classification) as shown in Figure 1.

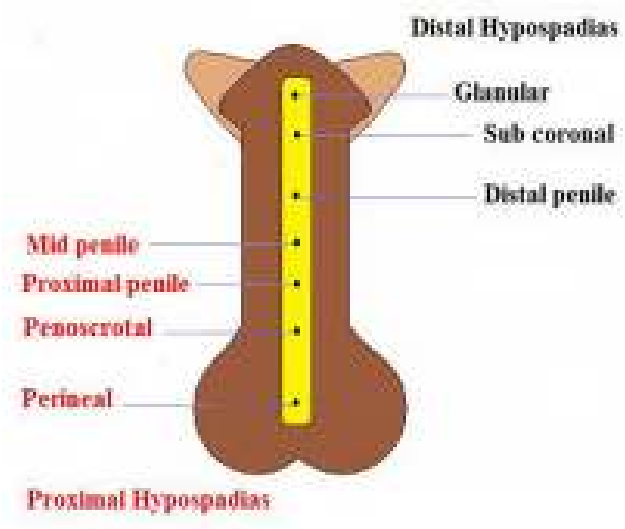

Figure 1: Classification of hypospadias

\section{Results}

Classification of hypospadias based on anatomical location of urinary meatus (Figure 1) Of the total 100 hypospadias, 74 had a distally placed urinary meatus and the rest had a proximally placed meatus. Each group was analysed further as shown in Tables 1 and 2.
Table 1: Distal penile hypospadias $(n=74)$

\begin{tabular}{|l|c|}
\hline \multicolumn{1}{|c|}{ Type } & No. \\
\hline Glanular meatus needing reconstruction & 01 \\
\hline Glanular and preputial anomalies & 04 \\
\hline Penile chordee in glanular meatus & 15 \\
\hline Subcoronal meatus & 38 \\
\hline Distal penile meatus & 16 \\
\hline
\end{tabular}

Table 2: Proximal penile hypospadias $(n=26)$

\begin{tabular}{|l|c|}
\hline Mid penile meatus & 06 \\
\hline Proximal penile meatus & 05 \\
\hline Penoscrotal meatus & 14 \\
\hline Perineal meatus & 01 \\
\hline
\end{tabular}

Detailed description of the position of the urinary meatus gives insight into penile development and hence to the final expectations after surgical reconstruction. This helps in preparing the child and caregivers on future expectations on cosmesis and psycho-sexual identity.

\section{Age at presentation for surgery}

Children were divided into four categories according to the age at presentation for surgery (Table 3).

Table 3: Age at presentation for surgery

\begin{tabular}{|c|c|c|c|}
\hline$<2$ years & $\mathbf{2 . 1 - 5}$ years & $\mathbf{5 . 1 - 1 0}$ years & $\mathbf{1 0 . 1 - 1 2}$ years \\
\hline 31 & 40 & 22 & 7 \\
\hline
\end{tabular}

Only $31 \%$ had presented for surgery before 2 years of age. In the age group between 2.1 to 5 years, $75 \%$ of children had delay in referral due to delay in the diagnosis and referral by medical officers. All others in the two older age groups, except 2 children with glanular hypospadias that would have been difficult to diagnose before 2 years of age, were advised to get surgical opinion but parents were non-compliant.

\section{Discussion}

The detailed meatal position based anatomical classification of $74 \%$ distal and $26 \%$ proximal hypospadias helped to predict the post-surgical expectations. In considering the age at presentation for surgery, only $31 \%$ had presented for surgery before 2 years of age. Delayed surgical reconstruction hinders achieving optimal anatomical outcome and subjects the child to undergo psycho-social changes some of which influence their adult sexual identity ${ }^{7}$. The role of the paediatrician as the primary care clinician in facilitating timely surgery by parental education and facilitating timely surgical referral needs appreciation.

\section{Conclusions}

In the study carried out at the LRH day surgical unit $74 \%$ of the hypospadias had a distally placed urinary meatus and $26 \%$ a proximally placed meatus. In this study only $31 \%$ presented for surgery before 2 years of age.

\section{References}

1. Wilcox DTW, Mouriquand PDE: Hypospadias. In: Thomas DFM, Duffy PG, Rickwood AMK editors. Essentials of Paediatric Urology. London: Informa Healthcare, 2008; 213-31. https://doi.org/10.3109/978020309145617

2. Schneuer FJ, Holland AJ, Pereira G et al. Prevalence, repairs and complications of hypospadias: an Australian populationbased study. Archives of Disease in Childhood 2015; 100(11):1038-43.

https://doi.org/10.1136/archdischild-2015308809

PMid: 26310454 
3. Viseshsindh W: Factors affecting results of hypospadias repair: single technique and surgeon. Journal of the Medical Association of Thailand 2014; 97(7):6948.

PMid: 25265766

4. Duckett JW: Hypospadias repair. In: Frank JD, Gearhart JP, Snyder III HM editors. Operative Paediatric Urology. Churchill Livingston, 2002; 150-60. PMCid: PMC150897

5. Snodgrass WT: Tubularized incised plate hypospadias repair. In: Frank JD, Gearhart JP, Snyder III HM editors. Operative Pediatric Urology. Churchill Livingston, $2002 ; 161-4$
https://doi.org/10.1016/S0094-

0143(02)00045-9

6. Handbook of $13^{\text {th }}$ European Paediatric Surgeons' Association congress and $59^{\text {th }}$ British Association of Paediatric Surgeons congress Rome 2012

7. Jones BC, O'Brien M, Chase J, Southwell BR, Hutson JM. Early hypospadias surgery may lead to a better long-term psychosexual outcome. Journal of Urology 2009; 182(4 Suppl): 1744-9.

https://doi.org/10.1016/j.juro.2009.02.089 PMid: 19692053 